(RESEARCH ARTICLE)

\title{
Effects of aerobic training on oxidative stress and inflammation in rats exposed to controlled emissions of carbon monoxide (CO) and nitrogen dioxide $\left(\mathrm{NO}_{2}\right)$
}

Tito S. Albérick I 1, *, Nsompi Florent 2, Messan Folly ${ }^{1}$, Kpatcha Tchazou ${ }^{3}$, Lawani M. Mansourou ${ }^{4}$ and Agbonon Amegnona ${ }^{3}$

\author{
${ }^{1}$ Respiratory, Hormonal and Gerontological Sports Explorations Unit. University of Abomey-Calavi (UAC), National \\ Institute of Youth, Physical Education and Sport (INJEPS), Benin. \\ ${ }^{2}$ Exercise Physiology and Biomechanics Research Unit, Marien Ngouabi University, Higher Institute of Physical Education \\ and Sport (ISEPS), Congo. \\ ${ }^{3}$ Physiology/Pharmacology laboratory, Faculty of Sciences, University of Lomé, BP: 1515 Lomé, Togo. \\ ${ }^{4}$ Biomechanics and Performance Laboratory. University of Abomey-Calavi (UAC), National Institute of Youth, Physical \\ Education and Sport (INJEPS), Benin.
}

Publication history: Received on 03 November 2020; revised on 08 November 2020; accepted on 11 November 2020

Article DOI: https://doi.org/10.30574/wjarr.2020.8.2.0408

\begin{abstract}
The objective of this study is to determine the effects of isolated exercise and those of repeated exercise on oxidative stress and the inflammatory process following exposure to carbon monoxide (CO) and nitrogen dioxide $\left(\mathrm{NO}_{2}\right)$.

Material and Method: 15 male Wistar rats, all eight weeks old, were randomly assigned to three groups. $\mathrm{CO}_{\text {and }} \mathrm{NO}_{2}$ were produced by the combustion of diesel fuel using a device contained in a sealed metal box and supplied with ambient air by a pump. The ranges of $\mathrm{CO}$ and $\mathrm{NO}_{2}$ concentrations to which the rats were exposed ranged from 35 to 45 ppm and 0.2 to $0.3 \mathrm{ppm}$, respectively. The aerobic workouts were performed on a rat treadmill. Blood samples were taken 24 hours after completion of handling at D4, D9 and D14. Variables studied were Malondialdehyde (MDA) and Tumor Necrosis Factor-alpha (TNF- $\alpha$ ).

Results: Aerobic endurance training after repeated exposure to $\mathrm{CO}$ and NO2 induces at the end of the first training block (D4) a significant increase ( $\mathrm{p}<0.01)$ in MDA and TNF- $\alpha$. On the other hand, the second block (D9) and the third training block (D14) induced a significant decrease $(\mathrm{p}<0.01)$ in these same parameters.

Conclusion: Aerobic exercise practiced in isolation exacerbates the oxidative stress and inflammation induced by exposure to $\mathrm{CO}$ and $\mathrm{NO}_{2}$. On the other hand, regular aerobic exercise in a less polluted environment, following five days of recovery, significantly reduces the high levels of oxidative stress and inflammation caused by repeated exposure to automobile pollutants.
\end{abstract}

Keywords: Pollution; Aerobic Exercise; Oxidative Stress; Inflammation.

\section{Introduction}

Inhalation of automotive pollutants induces blood disorders and especially non-communicable diseases in humans, making pollution a public health problem [1]. Globally, the number of deaths per year related to air pollution in urban and rural areas is about 6.5 million or $11.6 \%$ [2]. The main contributors to these pollutants are gasoline and diesel

\footnotetext{
${ }^{*}$ Corresponding author: Tito S. Albérick I

Respiratory, Hormonal and Gerontological Sports Explorations Unit. University of Abomey-Calavi (UAC), National Institute of Youth, Physical Education and Sport (INJEPS), Benin. 
combustion engines. In this sense, the number of pollution-related deaths in France, the reference country for diesel, varies between 17,000 and 48,000 representing a significant economic cost of about 33.6 billion US dollars [3]. According to Valentino et al. [4], several toxic gases, including nitrogen dioxide $\left(\mathrm{NO}_{2}\right)$ and carbon monoxide $(\mathrm{CO})$ are emitted by the diesel engine.

In the West African region and particularly in Benin, automobile pollution has become a major concern in recent years. Indeed, studies have shown that inhalation of automobile pollutants induces respiratory disorders in "motorcycle taxi" drivers [5] when exposed to a CO concentration higher than nine (09) ppm [6]. Cachon et al. [7] in an in vitro study also reported that exposure of human bronchial epithelial cells to particulate matter (PM2.5 and PM>2.5) collected in the city of Cotonou (Benin) induced significant secretion of pro-inflammatory cytokine proteins (TNF- $\alpha$ ) and an increase in the level of MDA, regardless of the duration of exposure $(24,48$ and $72 \mathrm{~h}$ ). Most of these studies took into account suspended particulate matter, which is a pollutant that can cause disease in children, adults and even athletes [8]. On the other hand, they do not make it possible to evaluate the effects induced by each pollutant in the appearance of communicable and non-communicable diseases.

Very recently Tito et al. [1] in an experimental and controlled study on the animal model have shown that acute exposure to $\mathrm{CO}$ and $\mathrm{NO}_{2}$ for at least 4 hours induces an overproduction of the reactive oxygen species (ROS) responsible for oxidative stress and an exacerbation of the inflammatory process which results in a significant increase in the concentration of TNF- $\alpha$. This is justified by the role of $C O$, which, once in the body following inhalation, binds to haemoglobin with an affinity 250 times greater than that of oxygen $\left(\mathrm{O}_{2}\right)$ [9]. The carboxyhaemoglobin $(\mathrm{HbCO})$ thus formed is a combination that inactivates a proportion of the haemoglobin in the blood, which is no longer able to play its role as an $\mathrm{O}_{2}$ carrier through the body [10]. $\mathrm{CO}$ can also bind to mitochondrial cytochromes, altering the electron transport chain and inhibiting aerobic ATP synthesis [11], thereby contributing to impaired cardiomyocyte metabolism. This could lead to ailments such as shortness of breath, general or peripheral fatigue and especially stroke, which are recurrent in large African cities such as Yaoundé, Abidjan, Lagos, Dakar, Ouagadougou, Niamey and Cotonou.

As air pollution is recognised as a source of damage to health, it could affect both sedentary people and sportsmen and women because of the significant presence of pollutants in the air inhaled during exercise. In this sense, physical exercise, particularly at weekends near major crossroads such as in Cotonou, Lomé, Abidjan, etc., leads to hyperventilation of air loaded with automobiles and environmental pollutants. Physical exercise, especially aerobic exercise, is recognized as one of the most effective non-pharmacological practices to improve health, quality of life and to control the high mortality risks associated with hypertension and obesity [12]. The question is, in what environment should we exercise to maintain our health?

Several studies have shown that hyperventilation in hot and humid climates may be responsible for the occurrence of bronchospasm in athletes $[13,14]$. In polluted environments, it promotes the deposition of inhaled pollutants in different parts of the respiratory system, which leads to inflammatory processes [15]. These pollutants are also able to cross the alveolar-capillary barrier to reach the bloodstream, leading to cardiovascular diseases, both communicable and non-communicable [15]. The airways of athletes are, therefore, frequently exposed to numerous allergens due to the high air exchange during exercise [16]. In addition, exercise-induced muscle damage promotes the infiltration of phagocytes (neutrophils and macrophages) at the site of injury. These changes that occur during exercise, therefore, increase the production of free radicals, leading to oxidative damage to biomolecules [17]. Studies on the animal model have shown that isolated aerobic exercise increases the level of oxidative stress not only in the blood but also in tissues such as skeletal muscle and the brain, heart, lungs, liver, kidneys and spleen [18-21]. Also, in this sense, studies on trained and sedentary subjects [22-24] have shown an increase in circulating levels of lipid peroxidation products in response to short-, medium- or long-term exercise. Other studies have shown that an adaptation phenomenon occurs in oxidative stress induced by even short-term exercise. Thus, prolonged physical training reduces the level of oxidative stress $[25,26]$. In this sense, an increase in the quantity pollutants inhaled during exercise would, therefore, lead to an increase in the harmful effects of air pollution when exercise is carried out in highly polluted environments. The results obtained vary according to the authors, taking into account the physical exercise and exposure modalities. Moreover, these results do not show the selective effects of each pollutant but the effects induced by physical exercise following exposure to the latter.

In view of the risks associated with pollution and the effects of physical exercise on the body, it is undoubtedly obvious that this practice in a polluted environment can be a source of damage.

Given that exposure to $\mathrm{CO}$ and $\mathrm{NO}_{2}$ induces oxidative stress and inflammation, what would be the role of physical exercise in combating the effects induced by pollution? The present research thus proposes to study the effects of 
regular physical exercise on rats subjected to repeated exposure to $\mathrm{CO}$ and $\mathrm{NO}_{2}$ based on a question that arises from the issue.

In what environment should physical exercise be practised and what physical exercise modalities can help the organisms be free from exposure to air pollutants?

\section{Material and methods}

\subsection{Biological material}

A total of fifteen (15) male Wistar rats aged two (2) months with body weights ranging from 174 to 206 grams were used. These animals were randomly divided into three batches consisting of one control and two experimental groups in three conventional cages of 5 rats each. Thus we have: Grp_Non Exposed_Non Trained (Non Exposed Non-Trained Group); Grp_Non Exposed_Trained (Non Exposed and Trained Group); Grp_Exposed_ Trained (Exposed and Trained Group). The lighting in the pet store was on a 12-hour daytime schedule over 12 hours at night. Access to water and food was ad libitum and the animals were acclimatized to the conditions of the animal house for one week before the experiments began.

\subsection{Description of the device for the production of $\mathrm{CO}, \mathrm{NO}_{2}$ and $\mathrm{O}_{2}$}

We used the protocol described by Tito et al. [1]. This device was in fact, composed of an ambient air motor pump (temperature $21^{\circ} \mathrm{C}$ and hygrometry $65 \pm 5 \%$ ) of the brand KF, NEUBERGER 78 Freidburg (A). This was then connected by a $7 \mathrm{~mm}$ diameter conductive pipe to a hermetically sealed metal box (B) $45 \mathrm{~cm}$ high, resting on a $35 \mathrm{~cm}$ long and 35 $\mathrm{cm}$ wide base with a low inlet and a high outlet. This box contains the gas oil combustion device (C), which is operated from the ambient air propelled by the motor pump through the low inlet to maintain combustion. Combustion of the gas oil produces in the metal box, $\mathrm{CO}$ and $\mathrm{NO}_{2}$, which escape through the high outlet and through a $8.5 \mathrm{~mm}$ diameter conducting pipe to a hermetic enclosure (D) $42 \mathrm{~cm}$ high, resting on a base $93 \mathrm{~cm}$ long and $49 \mathrm{~cm}$ wide. This hermetic enclosure houses the rats and the VENTIS MX4 EXPLO- $\mathrm{O}_{2}-\mathrm{CO}-\mathrm{NO}_{2}$ gas detector (E), which measures the $\mathrm{CO}_{2} \mathrm{NO}_{2}$ and then $\mathrm{O}_{2}$ concentrations coming from the metal box. The gas detector was thus programmed in the enclosure to tolerate the ranges of concentrations to which the animals were exposed: $\mathrm{CO}$ concentrations were between 35 and $45 \mathrm{ppm}, \mathrm{NO}_{2}$ between 0.2 and $0.3 \mathrm{ppm}$, and $\mathrm{O}_{2}$ between 20.4 and $20.6 \%$. In the event that the programmed concentrations exceeded, the gas detector was capable of emitting light beeps in order to preserve the physical conditions of the animals.

\subsubsection{Aerobic training on a treadmill: Description of the conveyor belt}

The treadmill (TR) with a compartmentalization system and a speed variator was designed by us to make the rats run (picture 1). It is equipped with a compartmentalization system that can simultaneously run nine (09) rats and is equipped with a speed variator. Thus, the speed of the treadmill was set at $20 \mathrm{~m} / \mathrm{min}$ for approximately 30 minutes (30 $\mathrm{min})$. The upper end of the conveyor belt was equipped with an electrified plate charged with 150 volts direct current. In this study, the aerobic exercise sessions lasted 30 minutes. These sessions included running on the treadmill without a slope $\left(0^{\circ}\right)$ at a moderate intensity (at $20 \mathrm{~m} / \mathrm{min}$ ).

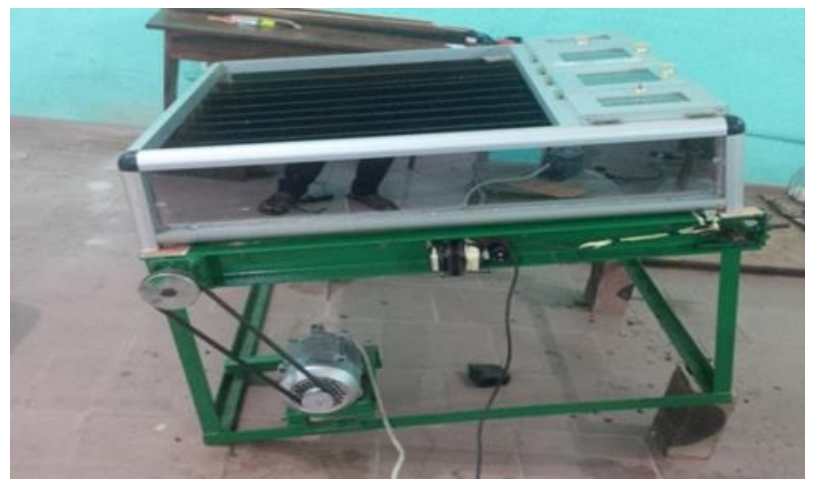


Picture 1 Treadmill for rats

\subsubsection{Getting used to running on a treadmill and determining the maximum aerobic speed}

One week before each handling, rats belonging to the groups Grp_Non Exposed_Trained; Grp_Exposed_Trained were subjected to a 5-day treadmill habituation protocol. For aerobic training, we therefore used and adapted the protocol of another [27]. Rats in these different groups were accustomed to running on a treadmill for 15 minutes per day at a speed of 20 meters per minute $(20 \mathrm{~m} / \mathrm{min})$ over three days. This allowed the animals to become familiar with the treadmill and thus limit the stress associated with its use. On the fourth day, after warming up on the treadmill for five minutes at a speed of six meters per minute $(6 \mathrm{~m} / \mathrm{min})$, the test to determine maximum aerobic speed was carried out. Immediately after the warm-up, the speed of the treadmill was increased by three meters per minute ( $3 \mathrm{~m} / \mathrm{min})$ every three minutes (3 min) until the animal was exhausted, i.e., when it could not run after three mechanical stimuli [28-30]. The maximum exercise capacity is defined as the maximum speed reached by each animal. The physical test was performed for each rat individually. The average speed at the group level was calculated and the rats were then subjected to treadmill training with the average working speed of the group.

Thus, in this study, for training purposes, rats were subjected to treadmill running at a moderate intensity corresponding to $50 \%$ and $60 \%$ of the maximum aerobic speed (VMA) obtained in the exercise test, for 30 minutes over nine sessions (three days of training and two days of rest over 15 days).

\subsection{Patterns of repeated exposure of animals to the pollutants $\mathrm{CO}$ and $\mathrm{NO}_{2}$}

Only the Grp_Exposure_Trained group of five rats was exposed to $\mathrm{CO}$ and $\mathrm{NO}_{2}$ for 4 hours, i.e., from 8 hours to 12 hours. This is repeated exposure of 4 hours, i.e. 4 hours/day for nine days. This exposure was divided into 3 exposure blocks of 3 days each. Each block was separated from the other by 48 hours of rest. In order to avoid the effects of the biorhythm on the dependent variables of the study, the exposures to the pollutants were given under the same conditions from 8 hours to 12 hours both in the group Grp_Trained_Exposure and in the other two groups: Grp_Non-Trained_Exposure and Grp_Non-Trained_Exposure. In fact, the latter underwent the same exposure protocol. They were not exposed to the pollutants, but were placed in another enclosure of the same dimensions and hermetically sealed, with the supply of ambient air provided by the motor pump. At the end of each exposure, they were then placed for two hours in a less polluted environment (absence of $\mathrm{CO}$ and $\mathrm{NO}_{2}$ ) for rest.

\subsection{Modalities of aerobic training after repeated exposure of animals to $\mathrm{CO}$ and $\mathrm{NO}_{2}$ pollutants}

At the end of the rest, the groups Grp_Exposed_Trained and Grp_Non Exposed_Trained were subjected to aerobic training divided into 3 blocks (Fig 1). Each block consisted of 30 minutes of aerobic exercise per day for three days. Between training blocks, there was a 48-hour rest period. At the end of each aerobic exercise session, the animals were then placed in a standard pet shop environment, i.e. the air was filtered according to the standard pet shop (AFS).

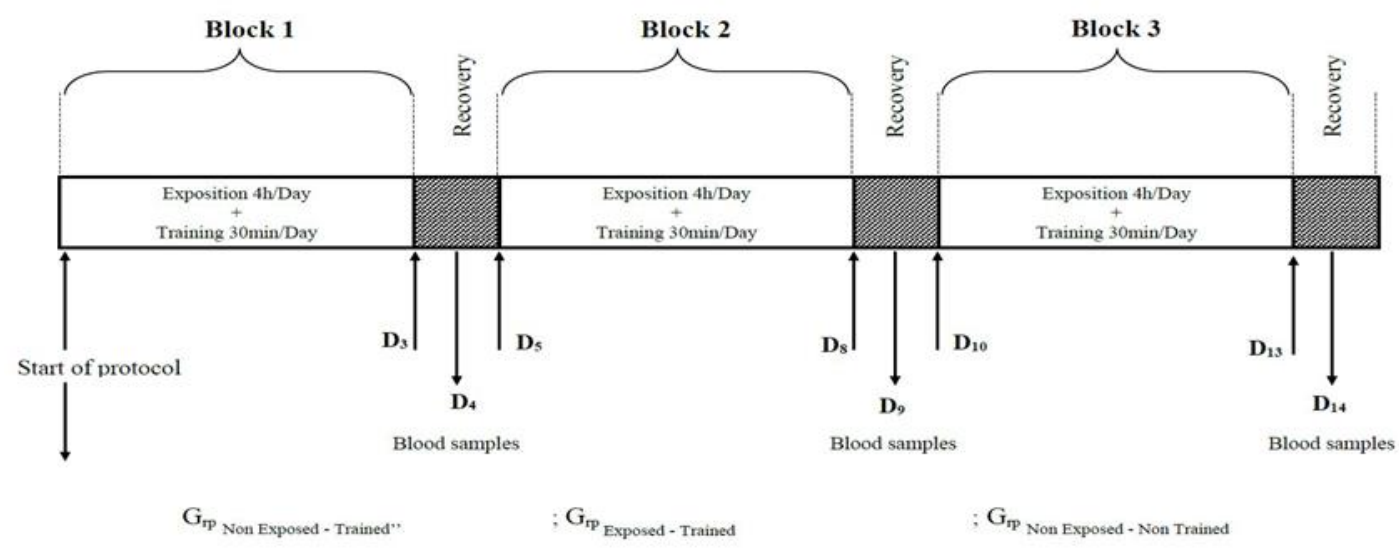


Figure 1 Data collection plan on the effects of 9 days of treadmill training of rats after repeated exposure to $\mathrm{CO}$ and $\mathrm{NO}_{2}$.

\subsection{Determination of biological parameters}

\subsection{1. (a) Biochemical parameters}

Blood sample and subsequent determination of Tumor Necrosis Factor-alpha (TNF- $\alpha$ ) and MDA (malonedihaldehyde)

Blood samples were taken 24 hours after the last training session in each block. For the three batches, blood samples were taken at the same time from the retro-orbital vein of the rats on days D4, D9, and D14. The blood was collected in tubes provided with an EDTA anticoagulant for subsequent analysis. In order to avoid any deterioration and external contamination, the blood samples collected were transported to the laboratory as soon as possible and centrifuged at $3000 \mathrm{rpm}$ for 15 minutes. The supernatant was stored at $-80^{\circ} \mathrm{C}$ until the assays were performed. The determination of the TNF- $\alpha$ concentration was done with the Enzyme-Linked ImmunoSorbent Assay (ELISA) kit (Ray Bio® Rat TNFalpha ELISAKit Protocol, Aachen, Germany). The MDA assay was performed according to the Agbonon and Gbeassor method [31] explained below.

\subsubsection{MDA dosing}

Lipid peroxidation was determined in serum by measuring the concentration of malondialdehyde (MDA) by adding 0.6 $\mathrm{mL}$ of $1 \%$ phosphoric acid $\left(\mathrm{H}_{4} \mathrm{PO}_{3}\right)$ and $1 \mathrm{~mL}$ of $1 \%$ thiobarbituric acid successively to a $200 \mu \mathrm{L}$ supernatant. The mixture was then placed in a water bath at $100^{\circ} \mathrm{C}$ for 50 minutes. The tubes containing the mixture were then cooled in an ice bath for 10 minutes. A concentration of $2 \mathrm{~mL}$ of 1-butanol was then added to the contents of each tube. The tubes were vigorously shaken and then centrifuged at $3000 \mathrm{rpm}$ for 10 minutes. The supernatant containing the thiobarbituric acidmalondialdehyde complex (TBA-MDA) was removed. The absorbance was read with the GENESYS 10S UV-visible spectrophotometer (Monaco, France. made in China, designed in the USA) at $535 \mathrm{~nm}$ against a blank. The blank was taken in the same way as the tubes used to determine $M D A$ except that the organ homogenate supernatant was replaced by distilled water. The standard curve was determined by the $M D A$ at concentrations of $0 ; 15.75 ; 31.5$ and $63 \mathrm{nM}$. The tests were repeated three times. 1,1,3,3-tetramethoxypropane $(M D A)$ was used as the standard to obtain the standard linear regression curve $(0-60 \mathrm{nM} ; \mathrm{Y}=0.03860 \mathrm{X}+0.04205)$. The correlation coefficient of the standard linear regression curve is $\mathrm{r}^{2}=0.9982$. The results were expressed in concentration (nM / mL).

\subsubsection{Determination of TNF- $\alpha$}

TNF- $\alpha$ concentrations were determined by the Enzyme-Linked Immuno-Sorbent Assay (ELISA) method (Rat TNF- $\alpha$ Picokine TM ELISA Kit). This is a heterogeneous phase enzyme-linked immunosorbent assay. It was performed according to the instructions of the supplier. The antibody adsorbed on a 96-well microplate contacted with a sample containing the antigen of interest for 1 hour. Then a biotinylated anti-TNF- $\alpha$ antibody was added after 4 washes. After 1 hour of incubation, excess antibody was removed by 4 washes and then streptavidin conjugated to peroxidase was added. After an additional incubation of 30 minutes, 4 washes were performed and then the substrate was added. After 1 hour of incubation, the addition of the hydrochloric acid solution stopped the reaction. The optical density was read at $450 \mathrm{~nm}$ versus $630 \mathrm{~nm}$, using a microplate reader. A standard range was performed in parallel to a standard to obtain the standard linear regression curve of the form $\mathrm{y}=\mathrm{ax}+\mathrm{b}(7.8 \mathrm{pg} / \mathrm{mL}-500 \mathrm{pg} / \mathrm{mL} ; \mathrm{Y}=0.0020 \mathrm{X}+0.0979)$. The correlation coefficient of the standard linear regression curve of the standard range is $r^{2}=0.9990$. The results thus obtained were expressed as a concentration ( $\mathrm{pg} / \mathrm{mL})$.

\subsection{Statistical analysis}

Continuous dependent variables and categorical independent variables were recorded using the Stat View 5 (version 5) software from Abacus concepts Inc. (Berkeley, CA, USA). Descriptive statistics were performed on the continuous dependent variables to determine their mean values with standard deviations. Three groups of rats with 3 modalities corresponding to 45 observations were studied. With this number of observations, the normality of the distributions was acquired greater than 30 . The homogeneity of the variances was observed and the ANOVA test, a parametric test, was performed for each continuous dependent variable on all 3 groups of rats. The Fischer PLSD test, as a post hoc binary test, was implemented if the ANOVA test showed a significant difference. For all tests, the cut-off point for significance was set at $\mathrm{p}<0.05$. 


\section{Results}

\subsection{Changes in mean body mass values and effects of aerobic training in less polluted environments on oxidative stress and inflammation}

The average value of the body mass was significantly reduced in the trained person (Grp_Trained) because $\mathrm{p}<0.05$ (table 1). The concentration of $M D A$ increased significantly $(\mathrm{p}<0.05)$ in the trained group at D4 compared to the control group (GT) but decreased significantly from D9 to D14. No significant difference was observed between the two groups at D14 ( $\mathrm{p}=0.0947)$. Regarding the TNF- $\alpha$ concentration, the trained group experienced a significant increase at D4 and then a significant decrease from D9 to D14 $(\mathrm{p}<0.01)$.

Table I Comparisons of mean values of MDA and TNF- $\alpha$ concentrations between Trained and Non-Trained groups

\begin{tabular}{|c|c|c|c|c|c|}
\hline & & $\begin{array}{c}\text { Grp_Non } \\
\text { Exposed_Trained } \\
(n=5) \\
m \pm s\end{array}$ & $\begin{array}{c}\text { Grp_Non Exposed_Non } \\
\text { Trained } \\
(\mathbf{n}=5) \\
m \pm s\end{array}$ & $\mathbf{P}$ & $\begin{array}{c}\text { Delta } \\
(\%)\end{array}$ \\
\hline \multicolumn{2}{|l|}{$\mathrm{MC}(\mathrm{g})$} & $146.933 \pm 17.826$ & $179.000 \pm 5.477$ & $0.0001^{* * *}$ & -17.91 \\
\hline \multirow{3}{*}{$\operatorname{MDA}(\mathrm{nM} / \mathrm{mL})$} & $\mathrm{D} 4$ & $13.626 \pm 0.923$ & $7.097 \pm 1.882$ & $0.01^{* *}$ & 91.99 \\
\hline & D9 & $12.019 \pm 2.045$ & $7.097 \pm 1.882$ & $0.01^{* *}$ & 69.35 \\
\hline & D14 & $9.429 \pm 1.449$ & $7.097 \pm 1.882$ & 0.0947 & 32.85 \\
\hline \multirow{3}{*}{$\mathrm{TNF}-\alpha(\mathrm{pg} / \mathrm{mL})$} & $\mathrm{D} 4$ & $78.250 \pm 16.769$ & $6.410 \pm 1.413$ & $0.01^{* *}$ & $\begin{array}{c}1120.7 \\
4\end{array}$ \\
\hline & D9 & $73.450 \pm 14.170$ & $6.410 \pm 1.413$ & $0.01^{* *}$ & $\begin{array}{c}1045.8 \\
6\end{array}$ \\
\hline & D14 & $57.850 \pm 11.967$ & $6.410 \pm 1.413$ & $0.01^{* *}$ & 802.49 \\
\hline
\end{tabular}

Grp_Non Exposed_Trained: unexposed and trained group; Grp_Non Exposed_Non Trained: unexposed and untrained group; n: actual; m \pm s: mean plus or minus standard deviation; MDA: malondialdehyde; $\mathrm{nM} / \mathrm{mL}$ : nanometer per milliliter; MC : body mass; g: gram; D4: day four; D9: day nine; D14: day fourteen, TNF- $\alpha$ : Tumor Necrosis Factor alpha; pg/mL: pictogram per millilitre; ${ }^{* *}$ : significant difference at $\mathrm{p}$ less than $0.01 ;{ }^{* * *}$ : significant difference at $\mathrm{p}$ less than 0.001 .

\subsection{Changes in mean body mass values and effects of aerobic training after exposure to CO and NO2 on oxidative stress and inflammation}

The average body mass value was higher in the exposed and untrained group (Grp_Exposed_Not Trained) because of $\mathrm{p}$ $<0.0001$ (table 2). For the changes in the exposed and trained group (Grp_Exposure_Trained), the mean values of $M D A$ concentrations were significantly higher at D4. But these concentrations decreased significantly at D9 and D14 because of $\mathrm{p}<0.01$. As the mean values of $T N F-\alpha$ concentrations were still at the same group level, they did not vary significantly at either D4 or D9, but a significant decrease at D14 was observed because of $\mathrm{p}<0.05$.

Table II Comparison of mean values of MDA and TNF- $\alpha$ concentrations between the Exposed and Trained groups

\begin{tabular}{|l|l|c|c|c|c|}
\hline \multicolumn{2}{|l|}{} & $\begin{array}{c}\text { Grp_Exposed_Non Trained } \\
\text { (n=5) } \\
\mathbf{m} \pm \mathbf{~ s}\end{array}$ & $\begin{array}{c}\text { Grp_Exposed_Trained } \\
(\mathbf{n = 5 )} \\
\mathbf{m} \pm \mathbf{~ s}\end{array}$ & $\begin{array}{c}\text { p } \\
\text { Delta } \\
(\%)\end{array}$ \\
\hline \multirow{2}{*}{ MC (g) } & $184.800 \pm 7.243$ & $146.933 \pm 17.826$ & $0.001^{* * *}$ & -20.49 \\
\hline \multirow{3}{*}{ MDA (nM/mL) } & D4 & $23.300 \pm 1.535$ & $29.895 \pm 3.101$ & $0.01^{* *}$ & 28.30 \\
\cline { 2 - 7 } & D9 & $29.380 \pm 1.331$ & $19.688 \pm 2.276$ & $0.01^{* *}$ & -32.9 \\
\cline { 2 - 7 } & D14 & $33.460 \pm 1.907$ & $15.802 \pm 2.713$ & $0.01^{* *}$ & -52.7 \\
\hline
\end{tabular}




\begin{tabular}{|l|l|r|r|r|c|}
\hline \multirow{3}{*}{ TNF- $\alpha(\mathrm{pg} / \mathrm{mL})$} & $\mathrm{D} 4$ & $90.930 \pm 8.806$ & $94.650 \pm 22.777$ & 0.17 & 4.09 \\
\cline { 2 - 7 } & $\mathrm{D} 9$ & $101.210 \pm 7.597$ & $81.050 \pm 16.432$ & 0.07 & -19.9 \\
\cline { 2 - 7 } & $\mathrm{D} 14$ & $109.850 \pm 9.285$ & $82.650 \pm 2.966$ & $0.01^{* *}$ & -24.8 \\
\hline
\end{tabular}

Grp_Exposed_Non Trained: Exposed and untrained group; Grp_Exposed_Trained: Exposed group four hours per day plus training; $\mathrm{n}$ : actual; $\mathrm{m} \pm \mathrm{s}$ : mean plus or minus standard deviation; MDA: malondialdehyde; $\mathrm{nM} / \mathrm{mL}$ : nanometer per milliliter; BW: body mass; g: gram; D4: day four; D9: day nine; D14: day fourteen, TNF- $\alpha$ : Tumor Necrosis Factor alpha; pg/mL: pictogram per milliliter; ${ }^{* *}$ : significant difference at $\mathrm{p}$ less than $0.01{ }^{* * *}$ : significant difference at $\mathrm{p}$ less than 0.001 .

\section{Discussion}

The objective of this study was to determine the deleterious effects of inhaled carbon monoxide (CO) and nitrogen dioxide $\left(\mathrm{NO}_{2}\right)$ and the biological responses to aerobic exercise after exposure(s) in male Wistar rats. A total of 15 eightweek-old male Wistar rats with body weights ranging from 174 to 206 grams were used. They were divided into three groups as follows: Non Exposed Non Trained Group (Grp_Non Exposed_Non Trained); Non Exposed and Trained Group (Grp_Non Exposed_ Trained); and a Group Exposed for four hours plus training (Grp_Exposed_Trained). The animals were acclimatized to the conditions in the animal facility for one week prior to the start of the experiments. Access to water and food was ad libitum and the lighting in the animal house followed a rhythm of 12 hours a day and 12 hours night. All manipulations started at eight o'clock (08:00) to avoid the effects of the biorhythm. In this study, two markers were used to assess the levels of oxidative stress and inflammation. These were MDA (Malondialdehyde) and TNF- $\alpha$ (Tumor Necrosis Factor alpha), respectively.

Analysis of the data showed that repeated exposure to $\mathrm{CO}$ and $\mathrm{NO}_{2}$ resulted in increases in the concentrations of $\mathrm{MDA}$ and TNF- $\alpha$ on days 4,9 and 14. These results complement the results of a recent study conducted by Tito et al. [1] which showed that 4 hour exposure to $\mathrm{CO}$ and $\mathrm{NO}_{2}$ significantly induced increases in mean concentrations of $M D A$ and $T N F-\alpha$. Thus, repeated exposure could be said to maintain over time the oxidative stress and inflammation induced by acute exposure to $\mathrm{CO}$ and $\mathrm{NO}_{2}$. Prolonged exposure to these pollutants could affect both sedentary people and sportsmen and women because of the significant air circulation during exercise. This would lead to ailments such as shortness of breath, general or peripheral fatigue and especially strokes, which are recurrent in large African cities such as Yaoundé, Abidjan, Lagos, Dakar, Ouagadougou, Niamey and Cotonou. In addition, physical exercise, particularly at weekends near major intersections, as in Cotonou, Lomé, Abidjan, etc., leads to hyperventilation of air laden with automobile and environmental pollutants.

Since regular physical exercise plays an anti-inflammatory role, this study investigated the effects of aerobic training with no exposure to pollutants as well as the effects of aerobic training after exposure to these same pollutants.

Indeed, the results showed that aerobic training in a less polluted environment induced a significant increase $(\mathrm{p}<0.01)$ in MDA concentrations on the fourth day (D4), then a significant decrease from the ninth day (D9). Then the concentration of $M D A$ no longer showed a significant variation by day fourteen (D14). Studies by Koh and Park [32], Gliemann et al. [33], Park and Kwak [34] and Kim et al. [35] have shown that regular moderate-intensity aerobic exercise improves redox balance, thus reducing oxidative stress, promotes immune function, leading to a reduction in the risk of disease and a reduction in inflammation. The increase in $M D A$ concentration observed at D4 could be related to the fact that animals, who never exercised, triggered the body's defence mechanism, resulting in a significant decrease in this same parameter at D9. The results of the present study are similar to those of Vilela et al. [36] who showed that 50minute aerobic endurance training of rats for three to four sessions per week for eight weeks reduced the risk of oxidative stress damage by significantly increasing superoxide dismutase (SOD) activity and then significantly decreasing glutathione (GSH) activity, indicating a reduction in oxidative stress. The decreases observed by these authors and those observed in our study could be linked to a phenomenon of adaptation to training [37]. This could justify the fact that the adaptation mechanism of antioxidants intervenes from five minutes of effort in response to the increase in free radicals [38]. This result confirms the reduction in stress represented by the decrease in $M D A$ observed in our study, even if the parameters studied in the two studies are not the same. Furthermore, the decrease in GSH levels observed in the study by Vilela et al. [36] could mean that glutathione was used to protect cells from oxidative damage [39]. This indicates that the trained subjects had significantly lower $M D A$ concentrations than sedentary subjects. Indeed, the comparative study by Elabed et al. [22] on oxidative stress in judokas and sedentary subjects showed that following an aerobic exercise session, trained subjects had significantly lower oxidative stress compared to sedentary subjects or less trained subjects, demonstrating that trained subjects have a better adaptation to free radical production compared to sedentary subjects. 
Given that physical exercise is considered as a source of prevention of many diseases, or even a therapy in its own right according to the French High Authority for Health (HAS) [40], this form of practice used in our study could be recommended to sedentary people in order to reduce the mortality rate linked to sedentary or physical inactivity, which is 5 million according to Lee et al. [41].

In inflammatory reactions, the results of this study show that aerobic training leads to a non-significant increase in TNF$\alpha$ concentrations at D4 and a significant decrease at D14. Our results are similar to those of Jahromi et al. [42] who showed that endurance training for 8 weeks decreases $T N F-\alpha$ concentrations. Indeed, in this study carried out on the human model, where 30 healthy young volunteers were subjected to running on a treadmill for 15 to 30 minutes at 50 and $70 \%$ of the maximum heart rate for eight weeks. But the results obtained by these authors do not allow us to really understand the variations in TNF- $\alpha$ until the last week or the end of the training. In the present study, rats were subjected to 30 minutes of treadmill running for nine days divided into three blocks: three days of endurance training and two days of rest. The results show that training in a less polluted environment leads, on one hand, to a significant increase in TNF- $\alpha$ concentrations at D4 and, on the other hand, to a significant decrease of the same parameter at D9 and D14. This observed decrease in TNF- $\alpha$ concentration could be linked to the fact that there was an overproduction of anti-inflammatory cytokines. In fact, according to Alves et al., [43] and Petersen and Pedersen [44], during exercise, skeletal muscle contraction produces $I L-6$ and stimulates anti-inflammatory cytokines such as $I L-1$ and $I L-10$ and inhibits the release of the pro-inflammatory cytokine TNF- $\alpha$, resulting in a reduction in TNF- $\alpha$. To explain the results obtained in our study, it is important to know that exercise stimulates the production of pro-inflammatory cytokines and superoxide $\left(\mathrm{O}_{2}-\right)$ which can cause tissue damage. Then, according to Nieman et al. [45], Ostrowski et al. [46] and Drenth et al. [47], exercise-induced pro-inflammatory cytokines trigger the generation of anti-inflammatory cytokines such as $I L-10, I L-1 r a$ which were not seen in our study and the transforming growth factor $\beta$ and the antioxidant SOD-2, which have protective functions. The role of these cytokines is to recruit neutrophils and monocytes from the damaged tissue to repair them [48]. Finally, during this process, anti-inflammatory cytokines and antioxidant mechanisms are initiated to limit the inflammatory reaction in response to exercise, which could lead to a decrease in $T N F-\alpha$ production after training in our study. This study is the first of its kind to our knowledge that shows such a variation in a relatively shorter period of time, thus contributing to the literature.

However, our results are contrary to those of Vilela et al. [36] who showed an increase in the concentration of TNF- $\alpha$ after aerobic training. These results are probably related to the age of the rats used, which is 24 months versus twomonth-old rats in our study. Then muscle ageing will be associated with sarcopenia, which will require more energy when running on a treadmill, because according to Vasto et al. [49] and Bruunsgaard [50], sarcopenia is associated with an increase in TNF- $\alpha$ levels as well as a high number of inflammatory cells such as neutrophils and monocytes.

Aerobic training, by reducing stress and inflammation levels, could therefore improve cardiorespiratory health and thus avoiding heart diseases, type 2 diabetes, rheumatoid arthritis, Alzheimer's and Parkinson's disease. So what will be the effect of training in a less polluted environment after exposure to $\mathrm{CO}$ and $\mathrm{NO} 2$ pollutants when it is known that exposure to these pollutants induces deleterious effects in the body? To answer this question, data from the literature provide information on the effects of aerobic training in polluted environments. Indeed, the work of Fashi et al. [27] has shown that aerobic training five times a week for four weeks in an environment rich in particulate matter (PM10) has protective effects on rats following PM10-induced inflammation. Aerobic exercise, therefore, inhibits $P M 10$-induced increases in $N F-K B$ and TNF- $\alpha$ gene expression. Another study by Vieira et al., [51] showed that regular aerobic exercise five times per week for five weeks in mice exposed to diesel pollutants also inhibited the increase in levels of reactive oxygen species induced by diesel emissions as well as neutrophil, white blood cell and TNF- $\alpha$ levels. No study to our knowledge takes into account gaseous pollutants, which could allow us to link inflammatory responses to this or that pollutant. Furthermore, no study to our knowledge has taken into account the effect of training in a less polluted environment after exposure to $\mathrm{CO}$ and $\mathrm{NO2}$. The results of our study showed that training in a less polluted environment after exposure to $\mathrm{CO}$ and $\mathrm{NO2}$ triggers an inflammatory process at the beginning. But both groups show no significant variation at either D4 or D9. In spite of this non-significant difference, one still observes a non-significant increase in the concentration of TNF- $\alpha$ at D4, and then a non-significant decrease at D9 in the group exposed for four hours plus training. But a significant decrease in the concentration of TNF- $\alpha$ was observed at D14. These results seem logical given that aerobic training in a less polluted environment reduces the levels of oxidative stress and inflammation on one hand, and on the other hand, aerobic training in a polluted environment inhibits the increase in stress-related gene expression and inflammation [27, 51]. It is, therefore evident that aerobic training in less polluted environments inhibits the exacerbation of deleterious effects induced by exposure to $\mathrm{CO}$ and $\mathrm{NO2}$. This first study of its kind thus makes a new contribution to the literature and could lead us to propose guidelines for physical exercise prescriptions to combat the deleterious effects of exposure to air pollution. 


\section{Conclusion}

The objective of this study was to determine the deleterious effects of inhaled carbon monoxide $(\mathrm{CO})$ and nitrogen dioxide (NO2) and the biological responses related to aerobic exercise sessions following exposure(s) in male Wistar rats. Results showed that prolonged exposure to $\mathrm{CO}$ and $\mathrm{NO2}$ only exacerbated stress and inflammation levels. In addition, to assess the effect of aerobic training done over several sessions on $M D A$ and TNF- $\alpha$ after repeated exposures to $\mathrm{CO}$ and $\mathrm{NO2}$, three important results were obtained: at the end of the first training block (D4), a significant increase in the values of the mean concentrations of the parameters related to oxidative stress and inflammation was observed. On the other hand, significant decreases in the mean values of these same concentrations were observed at D9 and D14. It could, therefore, be said that a phenomenon of habituation or adaptation has occurred, leading to a significant decrease in these parameters. These results show that aerobic training after repeated exposure to $\mathrm{CO}$ and $\mathrm{NO2}$ initially triggers oxidative stress and an inflammatory process but subsequently induces significant decreases in these same parameters. They also show the role played by two automobile pollutants in the appearance of health problems and the risks to which we are exposed when we stay in heavily polluted environments and practise physical exercise there. In addition, it is important to note that after repeated exposure to $\mathrm{CO}$ and $\mathrm{NO2}$, aerobic exercise practised regularly for at least 30 minutes a day with recovery periods has a protective effect on the body because it inhibits the expression of genes linked to oxidative stress and inflammation.

In this sense, these results seem to be close to the recommendations of the High Authority for Health (HAS) in 2018, which promote the practice of moderate-intensity physical exercise for at least 30 minutes a day. Our results also confirm the fact that physical exercise practiced regularly, particularly aerobic training, represents a non-drug treatment in the fight against the risk of cardiovascular diseases, diabetes, communicable and especially noncommunicable diseases. It could also combat cerebrovascular accidents, which are on the increase in large African cities. In addition, people who engage in physical exercise, especially in weekends at major intersections or major urban arteries, seem to be the most at risk. It is, therefore, conceivable to make environment pure for exercise to avoid the risks linked to this practice. The results obtained in this study also call for raising public awareness regarding the regular practice of physical exercise, in particular, moderate intensity aerobic exercise with two weekly sessions in less polluted areas and not near major intersections and main roads.

However, the results of this work need to be confirmed by other studies with a larger sample, a larger age group in both animal and human models.

\section{Compliance with ethical standards}

\section{Acknowledgments}

As part of implementation of this research, the authors thank Mr TITO M. Albert for financial support. We would also like to express our thanks to the managers of Physiology/Pharmacology laboratory (Togo) and Respiratory, Hormonal and Gerontological Sports Explorations Unit (Benin) for providing us with the necessary material to carry out this study.

\section{Disclosure of conflict of interest}

The authors declare no conflicts of interest.

\section{References}

[1] Tito A, Messan F, Togbenou K, Bio Nigan I, Dosseh K. Toxicological responses of wistar rats exposed to controlled emissions of carbon monoxide and nitrogen dioxide. WJRR. 2019; 8(5): 09-15. doi: 10.31871/WJRR.8.5.5

[2] Organisation Mondiale de la Santé. L'OMS publie les estimations nationales de l'exposition à la pollution de l'air et les effets sur la santé [Internet]; 2016 (consulté le 28 Avril 2017). Disponible: http://www.who.int/mediacentre/news/releases/2016/air-pollution-estimates/fr/

[3] Scarwell HJ. Les enjeux de la pollution de l'air en France : délaissement ou droit en jeu(x). Pollut Atmosphérique. 2017; 233. doi: 10.4267/pollution-atmospherique.6122

[4] Valentino S, Tarrrade A. Chavatte-Palmer P. Exposition aux gaz d'échappement Diesel durant la gestation : Quelles conséquences sur le développement foeto-placentaire? Apport des modèles animaux. Bull Acad Vét Fr. 2016; 169:No3. doi: 10.4267/2042/61628 
[5] Messan F, Lawani M, Akplogan B, Dansou P, Mama D, Hounkponou R et al. Bronchospasm diagnosis in motorcycle taxi drivers exposed to automotive pollutants in Porto-Novo. Open J Respir Dis. 2013; 3:13-20. doi: 10.4236/ojrd.2013.31003

[6] Lawin H, Ayi Fanou L, Kpangon AA, Hinson AV, Balmes J, Wanjiku J et al. Comparison of motorcycle taxi driver's respiratory health using an air quality standard for carbon monoxide in ambiant air: a pilot survey in Benin. Pan Afr Med J. 2018; 30:113. doi: 10.11604/pamj.2018.30.113.14975

[7] Cachon BF, Firmin S, Verdin A, Ayi-Fanou L, Billet S, Cazier F. et al. Proinflammatory effects and oxidative stress within human bronchial epithelial cells exposed to atmospheric particulate matter (PM2.5 and PM>2.5) collected from Cotonou, Benin. Environ Pollution. 2014; 185:340-51. doi: 10.1016/j.envpol.2013.10.026

[8] Tito A, Messan F, Nsompi F, Tito AM, Lawani MM. State of atmospheric pollution in West Africa : Health impact. Int J Curr Res. 2018; 10(09):73970-5. doi: 10.24941/ijcr.32455.09.2018

[9] Roughton FJW. The effect of carbon monoxide on the oxyhemoglobin dissociation curve. Am J Physiol. 1944; 141:17-31. doi: 10.1152/ajplegacy.1944.141.1.17

[10] Kimmel EC, Carpenter RL, Reboulet JE, Still KR. A physiological model for predicting carboxyhemoglobin formation from exposure to carbon monoxide in rats. J Appl Physiol. 1999; 86:1977-83. doi: 10.1152/jappl.1999.86.6.1977

[11] Brown SD, Piantadosi CA. In vivo binding of carbon monoxide to cytochrome c oxidase in rat brain. J Appl Physiol. 1990; 68:604-10. doi: 10.1152/jappl.1990.68.2.604

[12] Saunders KH, Shukla AP, Igel LI, Kumar RB, Aronne LJ. Pharmacotherapy for obesity. Endocrinol Metabol Clin. 2016; 45:521-38. doi: 10.1016/j.ecl.2016.04.005

[13] Messan F, Lawani MM, Marqueste T, Lounana J, Aimihoue D, Metodakou A et al. Assessment of MEF(25) in 156 children displayed to automobile pollution in Cotonou municipality. Mali Med. 2011; 26:16-21.

[14] Agodokpessi G, Ade G, Ahounou FJ, Gbenou DJ, Dansou HP. L'asthme induit par l'exercice de l'athlète en milieu chaud et humide. Rev Mali Med. 2012; 33.

[15] Cutrufello PT, Smoliga JM, Rundell K. Small things make a big difference: Particulate matter and exercise. Sport Med. 2012; 42:1041-58. doi: 10.2165/11635170-000000000-00000

[16] Tito A, Messan F, Nsompi F, Tito AM, Lawani MM. State of atmospheric pollution in West Africa : Health impact. Int J Curr Res. 2018; 10 (09):73970-5. doi: 10.24941/ijcr.32455.09.2018

[17] Kawamura T, Fuji R, Li X, Higashida KMI. Effects of exhaustive exercises, with different intensities, on oxidative stress markers in rat plasma and skeletal muscle. Sci Sport. 2018; 7. doi: 10.1016/j.scispo.2017.08.008

[18] Dalla Corte CL, de Carvalho NR, Amaral GP, Puntel GO, Silva LF, Retamoso LT et al. Antioxidant effect of organic purplegrape juice on exhaustive exercise. Appl Physiol Nutr Metab. 2013; 38:558-65. doi: 10.1139/apnm-20120230

[19] Kruger K, Frost S, Most E, Volker K, Pallauf J, Mooren FC. Exercise affects tissue lymphocyte apoptosis via redoxsensitiveand Fas-dependent signaling pathways. Am J Physiol RegulIntegr Comp Physiol. 2009; 296:1518-27 doi: 10.1152/ajpregu.90994.2008

[20] Bejma J, Ji L. Aging and acute exercise enhance free radical generation in rat skeletal muscle. J Appl Physiol. 1999; 87:465-70. doi: 10.1152/jappl.1999.87.1.465

[21] Radak Z, Asano K, Inoue M, Kizaki T, Oh-Ishi S, Suzuki K et al. Superoxide dismutase derivative prevents oxidativedamage in liver and kidney of rats induced by exhausting exercise. Eur J Appl Physiol Occup Physiol. 1996; 72:189-94.

[22] Elabed K, Masmoudi L, Trabelsi K, Hakim A. Effet d'un exercice de type aérobie sur le stress oxydatif : étude comparative entre judokas et sédentaires. Sci Sport. 2018; 33(2):90-7. doi:10.1016/j.scispo.2017.10.006

[23] Balc SS, Okudan N, Pepe H, Gökbel H, Revan S, Kurto־glu F et al. Changes in lipid peroxidation and antioxidant capacity duringwalking and running of the same and different intensities. JStrength Cond Res. 2010; 24(9):254550. doi: 10.1519/JSC.0b013e3181b22ab2

[24] Laaksonen DE, Atalay M, Niskanen L, Uusitupa M, Hanninen O, Sen CK. Blood glutathione homeostasis as a determinant of resting and exercise-induced oxidative stress in young men. RedoxRep. 1999; 4(1-2):53-9. doi: $10.1179 / 135100099101534648$ 
[25] Fatouros IG, Jamurtas AZ, Villiotou V, Pouliopoulou S, Fotinakis P, Taxildaris K et al. Oxidative stress responses in older men during endurance training and detraining. Med Sci Sport Exerc. 2004; 36:2065-72. doi: 10.1249/01.MSS.0000147632.17450.FF

[26] Miyazaki H, Oh-ishi S, Ookawara T, Kizaki T, Toshinai K, Ha S, et al. Endurance training in humans reduces oxidative stress following exhausting exercise. Eur J Appl Physiol. 2001; 84:1-6. doi: 10.1007/s004210000342

[27] Fashi M, Alinejad HA, Mahabadi HA. The effect of aerobic exercise in ambiant particulate matter on lung tissue inflammation and lung cancer. Iran J Cancer Preven. 2015; 8(3):e2333. doi: 10.17795/ijcp2333

[28] Vieira RP, Toledo AC, Ferreira SC, Santos AB, Medeiros MC, Hage M et al. Airway epithelium mediates the antiinflammatory effects of exercise on asthma. Respir Physiol Neurobiol. 2011; 175(3):383-9. doi: 10.1016/j.resp.2011.01.002

[29] Vieira RP, Duarte AC, Santos AB, Medeiros MC, Mauad T, Martins MA et al. Exercise reduces effects of creatine on lung. Int J Sport Med. 2009; 30(9):684-90. doi: 10.1055/s-0029-1224176

[30] Vieira RP, de Andrade VF, Duarte AC, Dos Santos AB, Mauad T, Martins MA et al. Aerobic conditioning and allergic pulmonary inflammation in mice. II. Effects on lung vascular and parenchymal inflammation and remodeling. Am J Physiol Lung Cell Mol Physiol. 2008; 295(4):L670-9. doi: 10.1152/ajplung.00465.2007

[31] Agbonon A, Gbeassor M. Hepatoprotective effect of Lonchocarpus sericeus leaves in CCl4-induced liver damage. J Herbs Spices Med Plants; 2009; 15:216-26. doi: 10.1080/10496470903139512

[32] Koh Y, Park KS. Responses of inflammatory cytokines following moderate intensity walking exercise in overweight or obese individuals. J Exerc Rehabil. 2017; 13(4): 472-6. doi: 10.12965/jer.1735066.533

[33] Gliemann L, Nyberg M, Hellsten Y. Effects of exercise training and resveratrol on vascular health in aging. Free Radic Biol Med. 2016; 98: 165-76. doi: 10.1016/j.freeradbiomed.2016.03.037

[34] Park SY, Kwak YS. Impact of aerobic and anaerobic exercise training on oxidative stress and antioxidant defense in athletes. J Exerc Rehabil. 2016; 12(2):113-7. doi: 10.12965/jer.1632598.299

[35] Kim JY, Sohn JH, Lee JH, Park JW. Obesity increases airway hyperresponsiveness via the TNF- $\alpha$ pathway and treating obesity induces recovery. PLoS One. 2015; 10(2): e0116540. doi: 10.1371/journal.pone.0116540

[36] Vilela TC, Effting PS, Pedroso GDS, Farias H, Lara Paganini, Sorato HR et al. Aerobic and strength training induce changes in oxidative stress parameters and elicit modifications of various cellular components in skeletal muscle of aged rats. Exp Gerontol. 2018; 106: 21-7. doi: 10.1016/j.exger.2018.02.014

[37] Calle MC, Fernandez M. Effects of resistance training on the inflammatory response. Nutr Res Pr. 2010; 4(4):25969. doi: 10.4162/nrp.2010.4.4.259

[38] Ji LL, Fu R. Antioxidant enzyme response to exercise and aging. Med Sci Sport Exerc. 1993; 25(2): 225-31. doi: 10.1249/00005768-199302000-00011

[39] Ryan MJ, Dudash HJ, Docherty M, Geronilla KB, Baker BA, Haff GG et al. Vitamin E and C supplementation reduces oxidative stress, improves antioxidant enzymes and positive muscle work in chronically loaded muscles of aged rats. Exp Gerontol. 2010; 45(11): 882-95. doi: 10.1016/j.exger.2010.08.002

[40] Haute Autorité de Santé. Note méthodologique et synthèse bibliographique. Activité physique et sportive pour la santé: promotion, consultation et prescriptrion chez les adultes [Internet]. 2018 (Consulté le 11 Mars 2019). Disponible: https://www.has-sante.fr

[41] Lee IM, Shiroma EJ, Lobelo F, Puska P, Blair SN, Katzmarzyk PTE. Effect of physical inactivity on major noncommunicable diseases worldwide: ananalysisofburdenof disease and life expectancy. Lancet L Engl. 2012; 380: 219-29. doi: 10.1016/S0140-6736(12)61031-9

[42] Alves JP, Nunes RB, Stefani GP, Dal Lago P. Resistance training improves hemodynamic hunction, collagen deposition and inflammatory profiles: experimental model of heart failure. PLoS One. 2014; 9(10): e110317. doi: 10.1371/journal.pone.0110317

[43] Alves JP, Nunes RB, Stefani GP, Dal Lago P. Resistance training improves hemodynamic hunction, collagen deposition and inflammatory profiles: experimental model of heart failure. PLoS One. 2014; 9(10): e110317. doi: 10.1371/journal.pone.0110317

[44] Petersen AM, Pedersen B. The anti-inflammatory effect of exercise. J Appl Physiol. 2005; 98: 1154-62. doi: 10.1152/japplphysiol.00164.2004 
[45] Nieman DC, Henson DA, Smith LL, Utter AC, Vinci DM, Davis JM et al. Cytokine changes after a marathon race. J Appl Physiol. 2001; 91:109-14. doi: 10.1152/jappl.2001.91.1.109

[46] Ostrowski K, Rohde T, Asp S, Schjerling P, Pedersen BK. Pro- and anti-inflammatory cytokine balance in strenuous exercise in humans. J Physiol. 1999; 515(Pt1): 287-91. doi: 10.1111/j.1469-7793.1999.287ad.x

[47] Drenth JP, Van Uum SH, Van Deuren M, Pesman GJ, Van der Ven-Jongekrijg J, Van der Meer JW. Endurance run increases circulating IL-6 and IL-1ra but downregulates ex vivo TNF-alpha and IL-1 beta production. J Appl Physiol. 1995; 79:1497-503. doi: 10.1152/jappl.1995.79.5.1497

[48] Nieman DC. Immune response to heavy exertion. J Appl Physiol. 1997; 82:1385-94. doi: 10.1152/jappl.1997.82.5.1385

[49] Vasto S, Candore G, Balistreri CR, Caruso M, Colonna-Romano G, Grimaldi MP et al. Inflammatory networks in ageing, age-related diseases and longevity. Mech of Ageing and Dev. 2007; 28(1): 83-91. doi: 10.1016/j.mad.2006.11.015

[50] Bruunsgaard $\mathrm{H}$. The clinical impact of systemic low-level inflammation in elderly populations. With special reference to cardiovascular disease, dementia and mortality. Danish Med Bull. 2006; 53(3):285-309.

[51] Vieira RP, Toledo AC, Silva LB, Almeida FM, Damaceno-Rodrigues NR, Caldini EG et al. Anti-inflammatory effects of aerobic exercise in mice exposed to air pollution. Med Sci Sport Exerc. 2012; 44(7): 1227-34. doi: 10.1249/MSS.0b013e3182b2877 